\title{
Agricultural Education and Training System Capacity Development for sub-Saharan Africa: the Role of InnovATE
}

Tom Gill \& Kristal Jones, International Agriculture Programs, The Pennsylvania State University, Pennsylvania, USA

\author{
$\&$
}

Tom Hammett, Office of International Research, Education and Development, Virginia Polytechnic Institute and State University, Blacksburg, Virginia, USA

\begin{abstract}
There is an urgent need to develop capacity in African agricultural education and training (AET) through innovative methods that achieve the goals of food security, economic development and poverty reduction. Innov ATE (Innovation for Agricultural Training and Education) is a five year, demand-driven USAID-funded program with a mandate for capacity development in AET systems in low income and emerging economies across the world. Though innov ATE's primary focus is on formal AET, the program's activities and findings are oriented toward developing capacity across agricultural knowledge and information systems (AKIS), which includes agricultural extension activities. Through innovATE's learn-design-train approach, the program bas developed capacity through various activities in SubSabaran Africa (SSA). These have included the generation of AET system studies on countries and thematic issues, the creation of an online Community of Practice, in-country assessment of AET systems in Uganda and the Democratic Republic of Congo, and the provision of training workshops for capacity development in Senegal and Mozambique. Evaluating the results of these activities provides the context for critical examination of the most effective approaches for AET system capacity development in SSA.
\end{abstract}

Key words: Agriculture Education and training, AKIS, extension, InnovATE, Sub-Sabaran Africa

\section{Introduction}

Africa, the continent with the fastest growing population, holds significant potential in meeting our planet's food needs in the $21^{\text {st }}$ century (NEPAD, 2013a). Lagging behind the rest of the world with lower staple crop yields and levels of agricultural technology use, much can be done to tap possible agricultural advancement that Africa promises (Bindraban, Loffler \& Rabbinge, 2008; Godfray et al., 2010). With the majority of Africans still employed in the agricultural sector, it is increasingly urgent to address pervasive capacity gaps hampering agricultural development. Indeed, capacity in the agricultural sector across sub-Saharan Africa has been weak for a long time, with many countries unable to finance or even prioritize capacity development activities, particularly since the midtwentieth century wave of independence from former colonial powers.

This situation was made worse in the era of structural adjustment following the Berg report, which encouraged reduction in public sector funding for development, and the provision of conditional loans by multilateral donors in return for the establishment of market-liberalizing 
economic policies by African governments (World Bank, 1981). The Green Revolution's suite of technologies of high yielding hybrid grains, irrigation, fertilizer and other agro-chemicals had not effectively penetrated the African continent and yields of major staples in the 1980s in Africa began to lag behind the impressive increases being witnessed across Asia and Latin America (Evenson \& Gollin, 2003). With a still nascent private sector, African economies were not yet at-scale to open up to the liberalizing forces of the global free market. As a result, African farmers and rural households were left unprotected against the volatility of world agro-product markets. There has since been widespread consensus that the broad-based structural adjustment programs propagated by the World Bank and other donors did not have the desired effects, and yet the legacy of more than twenty years of underinvestment in agricultural development in Africa remains (Friis-Hansen, 2000, Staatz \& Dembélé, 2008). This underinvestment is perhaps most notable in the weakened capacity at multiple levels in the agricultural sector (amongst others) that faces Africa today (FARA, 2007; AGRA, 2013).

However, since the turn of the millennium, African governments and international donors have started to increasingly prioritize agriculture as the primary vehicle for economic development. Indeed, agriculture remains the most important sector for most sub-Saharan African countries, both in terms of percentage of workforce employed and percentage of GDP (Brooks, Zorya \& Gautam, 2012). In 2003, the African Union launched the Comprehensive Africa Agriculture Development Programme (CAADP), an agreement among African governments to commit financial resources adequate to underwrite the rhetoric about the importance of agriculture for Africa. Under CAADP, African governments pledged to increase the share of public expenditure on agriculture to $10 \%$ of their total budget outlay, in order to realize $6 \%$ growth in agricultural GDP per year. However, only twelve countries have so far attained the $10 \%$ outlay and African agriculture continues to lag behind (NEPAD, 2013b).

All is not lost, however, as rising interest among the international community in Africa's role as increasingly strategically important in the global fight against food insecurity has led to increasing foreign investment in developing African agriculture. There has been arrival of new players led by private foundations (e.g. the Gates Foundation-influenced Alliance for a Green Revolution in Africa) (see Brooks et al., 2009). This interest has been matched with increasing public sector funding, such as the Feed the Future (FTF) Program, the US Government's global food security initiative, part of the Global Agriculture and Food Security Programme (GAFSP). FTF has significant focus on Africa, as twelve of its nineteen focus countries for technical assistance and investment in agricultural development are located in sub-Saharan Africa (SSA) (see Feed the Future, 2014 for an overview of countries and activities).

With this new global emphasis on African agricultural development, there is a rising awareness, from both internal and external stakeholders, of the need for local capacity development for African agriculture (UNDP, 2012). This capacity development is urgently needed to effect sustainable growth and impact of investment in the agricultural sector. Recent studies (Lechtenberg et al., 2014; Eicher \& Haggblade, 2013; Spielman et al., 2008) have highlighted the need to build both human and institutional capacity in African agricultural education and training (AET) systems through innovative methods that achieve the end goals of food security, economic development and poverty reduction. Strong and effective AET systems for Africa have the potential for supplying the capacity development boost needed to achieve these goals (Acker \& Gasperini, 2009). However, currently, African AET institutions have weak capacity, including outdated curricula, underutilized and under-resourced facilities, ineffective governance, managerial and administrative structures, and weak linkages with external partners in the international community. Compounding this, there is a 
dearth of trained agricultural professionals at multiple levels and across multiple disciplines. These professionals may lack not only technical capacity (depth in subject material) but also functional capacity (including soft skills of leadership, administration and management). This article addresses the role of an FTF-funded global program, innovATE (Innovation for Agricultural Education and Training), in capacity development in SSA. Central to the innovATE program is developing and undertaking strategic activities to assess and begin to meet these gaps in AET capacity development in SSA.

\section{Conceptual framework}

Most official definitions of capacity and capacity development are very broad (Otoo, Agapitova \& Behrens, 2009). Arguably the most widely used and clearest definition of capacity for development is the one espoused by the Organisation for Economic Co-operation and Development, which defines capacity as "the ability of people, organizations and society as a whole to manage their affairs successfully" (OECD, 2006). Although capacity in this sense (and in the term "capacity development") is articulated in the singular, it is more appropriate to think of this "ability" in the plural, i.e. in terms of a wide range of capacities. These capacities range from an ability to access the most basic of resources to supply human needs - water, food, healthcare - to the ability to provide visionary leadership and strategic planning at a range of levels of different scale. Capacities can be technical (in terms of depth of knowledge and ability in a certain domain) or functional, involving cross-cutting, transferable skills (such as management and leadership abilities). "Capacity" as an inclusive, overarching term involves the availability of a wide-range of resources (physical, financial, human, etc.), the effectiveness and efficiency with which these resources are acquired and used, and the ability of this resource management to generate sustainable social and economic development (Otoo, Agapitova \& Behrens, 2009).

If this is how we can understand "capacity", what then does capacity development (CD) involve? It can be seen as both a process, e.g. working towards increasing agricultural growth, and as an objective of development, e.g. targeted training of individuals or organizations. Most frequently, however, $\mathrm{CD}$ is seen as a combination of both, e.g. a process to achieve certain objectives (CAADP, 2009). The World Bank proposes that CD is "a locally-driven process....to achieve a development goal” (Otoo, Agapitova \& Behrens, 2009), while the United Nations defines CD as fundamentally about achieving measurable development through "transformation that is generated and sustained from within" (UNDP, 2009). This transformation process involves experimentation and learning, and in many cases is much more fluid than following rigid blueprint models for a single type of form or function. This is arguably the explanation for the shift in terminology in the past twenty years away from capacity "building" (implying following prescribed models for enhancing capacity) towards capacity "development" (implying an organic process) (Horton, 1999). There is thus consensus that $\mathrm{CD}$ does not follow one set approach and instead operates through many different avenues and dimensions (Bolger, 2000).

For African agriculture, the African Union (AU) has laid out its CD strategy through the CAADP framework. The AU's vision for the continent is to see capacity developed in a sustainable manner so that Africans can direct their own futures. Interestingly, however, the AU adopted and subsequently adapted a non-African definition from the OECD, framing CD as "the process whereby over time, people, organisations and society as a whole create, obtain, unleash, adapt, strengthen and maintain capabilities to set and achieve their own goals on a sustainable basis" (NEPAD, 2014, adapted from OECD, 2006). CAADP's framework for this definition is on four 
dimensions of CD: individual, institutional, societal-coalitions/networks, and enabling environment. This framework is a more nuanced version of the United Nations framework, which portrays CD in three dimensions: individuals, organizations, and enabling environment (Figure 1) (FAO, 2010; UNDP, 2009). Under both the UN's and the AU's framework, the individual level represents personal skills, knowledge and experience acquired through formal and informal trainings and networks. The organizational level represents the internal structure of an institution, and the policies and procedures that govern that institution. The enabling environment represents the overall framework in which individuals and organizations operate, and the rules and regulations that govern those relationships. The AU framework's fourth dimension - societal-coalitions/networks - teases out another realm of actors, which it identifies as non-state and beneficiary groups, such as farmers or the non-profit community.

In this paper, we apply the FAO framework (Figure 1) of three interlinked dimensions (individuals, organizations, and the enabling environment), while also recognizing the nuances of the CAADP framework and its additional dimension. We will refer to these dimensions throughout this paper as "levels" of capacity development, based on UNDP language. We view the UN framework as adequate for our analysis, by incorporating elements that emphasize strengthening citizenry responsibility and participation and the inclusion of target groups such as the oft-marginalized (e.g. women, youth) into CD at the individual and/or institutional levels, and elements that emphasize inclusive policy making and implementation and the inclusion of target groups such as nongovernmental advocacy organizations into CD in the enabling environment. The interrelationships between the three levels are important to note; they do not operate independently of one another. The training of individual leaders and agents of change helps to develop stronger institutions; institutions provide different rules and environments in which individuals can develop their capacity, and thus, stronger institutions can (and should) lead to individuals with enhanced capacity. Meanwhile, the capacity development of institutions and individuals is simultaneously impacted by the enabling environment(s) in which they operate; on the other hand, individuals and institutions with enhanced capacity can be effective agents of change in the enabling environment.

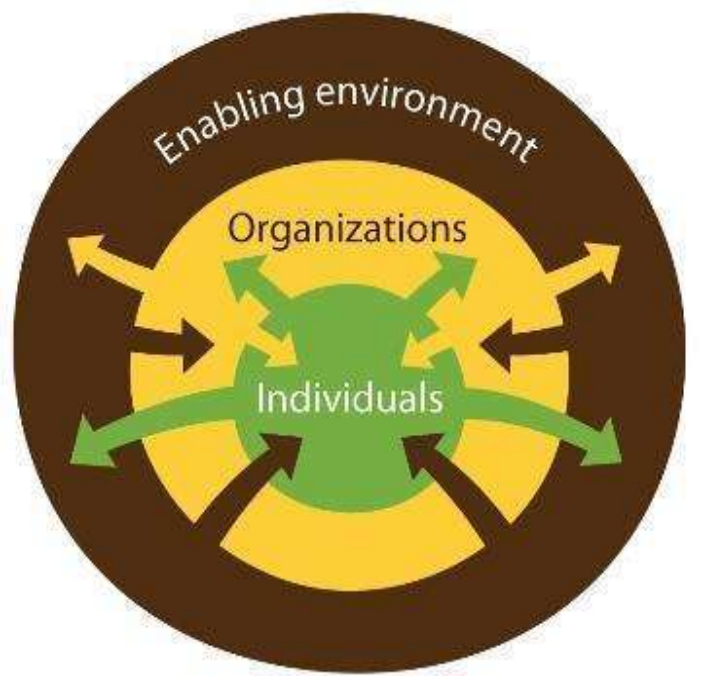

Figure 1. A conceptual framework of capacity development (from FAO, 2010).

It is useful to think of capacity development in terms of the whole system, incorporating all three levels, multiple capacities and multiple pathways to successful, sustainably enhanced capacity. 
However, the question then becomes one of how to institute effective, positive change in capacity at different levels. The US government's capacity development approach focuses primarily on projects that look to effect change at the individual and/or organizational levels, through its "human and institutional capacity development" (HICD) portfolio. The current USAID approach to HICD, in both a larger sense and within the context of agricultural development, stresses the need to engage both institutions and individuals in a multi-pronged process entire process (USAID, 2010). Gilboy et al. (2010) describe this as a more holistic and integrated process, representing a shift from previous models of capacity development that have primarily focused on change at the individuallevel through a "best and brightest" approach to selecting students for long-term academic training. This holistic approach emphasizes identification of institutional and national needs, support for individual training to address those needs, and the building of long-term connections between US and developing country institutions (Jones et al., 2012).

InnovATE (Innovation in Agricultural Education and Training) is a critical piece of the HICD approach and portfolio of capacity development in the agricultural sector for Feed the Future. A five-year, "demand-driven" (i.e. by overseas stakeholders) program, InnovATE has the goal of developing individual and organizational-level capacity in agricultural education and training (AET) systems in low and middle-income countries around the world. The target audiences for innovATE includes AET institutions around the world, international donors, NGOs, and private sector organizations (e.g., consulting companies working in AET, agriculture enterprises). The underlying assumption is that enhanced AET capacity is required to catalyze growth and innovative advances in the agricultural sector in these countries, the majority of which still largely depend on agriculture as their primary economic engine for development. InnovATE's mandate is to develop this capacity across the formal and non-formal education continuum from primary to tertiary and adult education. In order to fulfill this mandate, innovATE engages in a CD process with stakeholder institutions to build skills and competencies to fill the gaps in the agricultural sector between current (and projected) workforce supply from in-country educational systems and current (and projected) workforce demand. By working through the formal educational system, innovATE models one important capacity development pathway that has the potential to generate sustainable change. The remainder of this paper will use the CD frameworks overviewed above to describe and evaluate several activities that the innovATE program has undertaken, the impact of those activities on developing capacity, and the implications of developing AET system capacity for sub-Saharan Africa.

\section{Methods}

\section{Learn, Design, Train model for developing AET capacity}

InnovATE's model for developing capacity in AET systems is structured into three components with iterative and synergistic methodologies: Learn, Design and Train:

- Learn: This component involves the collection of baseline data, synthesized into accessible knowledge formats to enhance wider understanding about the current state of AET systems globally. The Learn component involves gathering information and creating AET knowledge, making this information accessible to a global audience, and fostering the development of an AET Community of Practice (CoP).

- Design: In order to identify current gaps in AET systems and synthesize lessons learned from prior AET system investments in countries around the world, activities under the Design 
component include the development of tools to identify these gaps, needs assessments of current AET systems in specific countries (at the request and invitation of in-country partners), and the development of models of AET system functions and their influence on agricultural innovation systems to guide AET investment decisions of donors and institutions.

- Train: Training needs vary depending on the level of human capacity and stage of institutional development at targeted AET institutions and systems. InnovATE's response has been to develop two types of training: 1) training for intervention at the scale of entire national AET systems, and 2) training for intervention within individual AET institutions or specific educational levels (e.g., secondary, university). In addition, innovATE provides country-specific support for administrative and student services and technical assistance to support AET system CD, completes and disseminates training modules, and completes and circulates country and thematic studies.

Examples of capacity development under innov ATE from SSA

We present several examples of CD activities in sub-Saharan Africa, focusing on the methods used to strengthen individual and institutional capacity, and the linkages between the two levels. The results section then expands upon the activities, providing specific examples of how these activities led to $\mathrm{CD}$ at multiple levels. Under Learn, we describe the types of resources generated by innovATE to present new knowledge, including digital and online media that can be used by individuals and institutions to implement new activities. Under Design, we present examples of needs assessments (which we term "scoping visits") of the AET systems conducted in Uganda and the Democratic Republic of Congo (DRC). Finally, under Train, we present the cases of a training for professionals in Senegal on incorporating gender into agricultural and nutrition education, and a training workshop with the Regional Universities Forum for Capacity Building in Agriculture (RUFORUM) on CD for higher education institutions.

\section{Learn activities}

The foundational component of innovATE activities is to generate materials, both print and digital, that can inform specific efforts and approaches for CD in AET systems in low and middle income countries. In print form (available for download from the program website), innovATE generates country-specific AET studies that identify where CD activities are needed and thematic studies of key issues in AET system capacity building. The country and thematic studies are based on secondary literature and key informant interviews, and present a "lay of the land" view of a particular country or thematic issue. As a component of CD, these studies provide a starting point for Design and Train activities for innovATE, as well as for anyone with interest in working the specific countries and thematic areas discussed. They therefore have the potential to contribute to both individual and institutional CD, depending on their use. Recent country studies for subSaharan Africa have included Mali, Uganda and the DRC, with the latter two providing the basis for scoping visits (described in the Design section below). Thematic studies have focused on issues such as "gender in AET", and "AET in post-conflict settings" (Zseleczky, Van Houweling \& Christie, 2013). With these materials, innovATE functions as a thought leader, providing timely and thorough analyses of the current state of AET systems globally, and then making that information available for use by individuals or institutions for whom these materials are relevant.

The knowledge and information generated through Learn activities is shared via a digital Community of Practice (CoP) platform (Virginia Tech, 2015), which supports CD in several ways. 
Once registered, CoP users register and create a profile, so that users can network on topics and geographic regions of common interest. The CoP supports ongoing threaded discussions, continually updating posted materials and resources on capacity building in AET systems, and hosting an archive of innovATE materials. The discussions allow people to develop linkages with other AET system professionals and provide a platform for ongoing exchange, which develops individual capacity. These relationships and exchanges also have the potential to enhance institutional capacity and influence the enabling environment over the long run, as individuals engage in an iterative process of learning and sharing their experiences and lessons learned. For example, following up on the gender in agriculture workshop held in Senegal (described in the Train section below), innovATE created a French-language space for workshop participants to continue the conversations started in person. Materials from the workshop, in French, are also posted in this space, providing a regionally relevant resource for individuals and institutions looking for resources on gender in AET.

\section{Design activities}

Once the research on AET capacity gaps through the country and thematic studies is completed, the next step is to develop strategies to meet gaps in skills that hinder AET capacity development designing interventions to meet gaps (skill needs, etc.) A natural first step is to field a team of experienced specialists to do ground checking and draft a set of recommendations for investment. From the several AET scoping visits conducted to-date across the world, two serve as examples for SSA. First, at the request of the USAID Mission in Uganda, and working with RUFORM, a regional NGO working to improve higher education, and the University of Makerere, innovATE sent a team of three people for one week to Uganda in November 2013. The purpose of the assessment was to devise a plan to develop the capacity of Makerere's Department of Agribusiness and Natural Resource Economics (DANRE) graduate and undergraduate programs so that they are more responsive to the needs of policy makers, agribusiness employers and entrepreneurs throughout the Ugandan agricultural sector.

Secondly, at the request of USAID/DRC, InnovATE conducted a scoping visit in August 2014 to assess the technical and vocational education and training (TVET) system in southern Katanga Province (the mining basin) to meet the needs of the workforce and enable alternative agricultural livelihoods. The three-person innovATE team worked with the University of Lubumbashi in DRC for three weeks to conduct the assessment. The main focus of this assessment was how to bridge the needs of the mining sector with the food security needs of the local population, through developing capacity in young men and women to find employment or undertake their own microenterprises.

\section{Train activities}

InnovATE's Train activities build on previous Learn and Design components while also providing a platform for future learning and capacity development. One training example is "Strategies and tools for integrating gender in the agriculture and nutrition curriculum", a three-day regional workshop, held in Senegal in June 2014. Participants were invited from across the Francophone region in Africa including Mali, Guinea and Burkina Faso. They were a mix of agricultural education professionals and professionals/stakeholders in other areas of agriculture, including government officials, representatives of the private sector and development actors. Inviting a diverse group of stakeholders to trainings increases the cross-level capacity development possibilities; the presence of 
government officials is especially important as a linkage to developing capacity in the enabling environment.

During each morning session, key speakers provided a framework for understanding gender analysis and gender issues in agriculture and nutrition and panels of private sector and university experts shared their experiences with gender in their respective fields. Group discussion followed each presentation, allowing participants to clarify and expand upon points made by the key speakers. Each afternoon, participants engaged in small group work to discuss the meaning of gender integration into curricula and research programs and to identify opportunities for incorporating gender. The final output of the group work included identifying substantive areas and courses in which gender could be integrated, the creation of a class outline for a specific course that could include gender, and the development of examples of case studies that could be included in the class outline.

Another example of innovATE's training activities in SSA is a CD training workshop "Opportunities for Transformative Change in African Universities", held during the bi-annual RUFORUM conference in July 2014. The one-day training included 41 participants representing AET institutions in 25 countries across SSA. This training was designed to help regional institutions gain a deeper understanding of the challenges for development of higher education in agriculture on the African continent, and the opportunities by others to meet those challenges. Participants were asked to identify the key challenges facing their institutions' capacity development and develop an action plan to meet those challenges. Participants were also assisted in starting the process to build a network to help each gain the resources and collaboration necessary to meet those challenges.

\section{Results}

Learn findings

Activities under the Learn phase of innovATE's approach have supported multi-level CD in several ways. The country studies support work primarily in developing individual and institutional capacity during the Design and Train phases, by providing insight into the mechanisms that link these levels of change. In addition, they characterize the policy environment and can support HICD activities that also have the potential to contribute to changes in the enabling environment. For example, the DRC country background study situated the AET system within the post-conflict context and identified appropriate mechanisms for supporting workforce development through AET system development given the displacement in the country. A key stakeholder in this work based in the DRC is the mining industry which needs a workforce with similar skills at those needed in the agricultural sector (i.e., mechanical repair, product processing and transportation, and water use and management) will be the skills (Baharanyi et al., 2014). By understanding the relevant stakeholders and context within which agriculture occurs in the DRC, the scoping team was able to tailor their stakeholder interviews to the country-specific situation.

Thematic studies offer a different, complementary approach to integrating background information on CD across levels. The thematic studies make extensive use of case studies, identified in the secondary literature, and by categorizing multiple case studies, the thematic studies synthesize individual issues within the given theme into a comprehensive understanding of how the theme relates to AET. The thematic study on gender, higher education and AET, for example, identifies the social and cultural elements of gender and agriculture as they relate to higher education in SSA, and identifies leverage points at the individual, institutional, and policy/social levels (Zseleczky, Van Houweling \& Christie, 2013). This thematic study informed the workshop on incorporating gender 
into agricultural and nutrition education held in Senegal in 2014, and has also supplemented findings from scoping visits that have identified gender needs in AET system CD through the design process.

Perhaps the most dynamic results from innovATE activities have come from the Community of Practice. The CoP as a resource has several audiences: USAID mission staff who are interested in including AET system capacity development in their work; U.S. university faculty and students interested in sharing their work and connecting to others in their field; and development practitioners, many of whom are extension agents or agricultural advisors, and are looking for specific information about developing training capacity on particular topics and in particular places. This last group, development practitioners, has been by far the most active in the CoP, and has generated conversations and resources that address not only individual but institutional and enabling environment capacity development. Opening the CoP up to all types of AET system professionals has created opportunities for cross-level interactions that can support more holistic CD. For example, one forestry agent who participated in the workshop in Senegal has been discussing government policies for supporting women in higher education with other CoP participants, bringing an important and often under-incorporated, perspective to the conversations.

\section{Design findings}

The two scoping visit examples demonstrated the complex and integrated nature of CD. The scoping visit to Uganda revealed the importance of building relationships between higher education institutions, policy makers and agribusiness, in order to develop programs that equip students with necessary interdisciplinary skills to enter the workforce upon graduation. The findings of the assessment highlighted the need to re-organize and mobilize the DANRE faculty around policy and agribusiness issues. The innovATE team and Makerere University counterparts recommended a three-pronged strategy for this mobilization: 1) strengthen the linkages between agribusiness stakeholders and DANRE faculty and students in the development of policy and agribusiness priorities, 2) enhance the policy and agribusiness orientation of DANRE degree programs, and 3) upgrade faculty delivery of those programs through the introduction of more active learning techniques. These recommendations highlighted the integrated nature of developing capacity at the individual level (through enhancing faculty delivery skills and student learning outcomes), while simultaneously developing capacity (through program development and enhancing stakeholder linkages) at the institutional level.

Meanwhile, three findings emerged from the assessment in the DRC. First, the scoping visit to DRC highlighted that the agriculture sector is not insulated from needs in other sectors. Developing capacity in one sector can be leveraged to enhance capacity in other sectors. This is particularly true of soft (functional) skills, which are more easily adapted and transferable to other contexts. An important opportunity to bridge sectors is through the use of TVET (Technical and Vocational Education and Training). In this case, the possibility of using TVET to connect the mining industry and agriculture was identified as a way to develop individual capacities in transferable skills that would enable trained workers to operate in either sector, e.g. through machine operator training or through value chain development. Secondly, the DRC scoping visit highlighted that CD in functional skills must be complemented by CD in technical skills. In particular, this case highlighted the urgent need for technical training in food processing and packaging in important agricultural value chains to the Katanga region, such as tomatoes, peanuts, potatoes and animal feed products. Developing these skillsets would enable those working in the agricultural sector to access income-generating opportunities, providing viable alternative livelihoods than wage-labor in the 
mines. Finally, the DRC scoping visit indicated the need to consider CD across the realm of agricultural knowledge and information systems. It was recognized that development in functional and technical skillsets of individuals would only be transformational at higher levels if applied through community engagement. There was a clear need for advisory and technical assistance service to provide the support for "agri-preneurs" who wanted to employ their new skillsets to start their own microenterprises. The use of Farmer Field Schools was familiar to many in the region and was recommended as a suitable vehicle to bridge formal and non-formal delivery methods.

\section{Train findings}

One key result of the workshops focused on individual capacity development in AET was the need to focus discussion of change on areas that are actionable for the individuals being trained. In the Senegal training (which was targeted mainly at agricultural education professionals), emphasizing teaching plans that could be adjusted by individual faculty supported immediate capacity for those individuals. At the same time, focusing on curricula and syllabi creates a link between individual and institutional capacity by encouraging professionals to institutionalize the changes that they are incorporating as individual teachers. In addition, the iterative nature of the Learn, Design, Train process means that $\mathrm{CD}$ activities in one phase provide the foundation for future work. Over the medium term, the information generated and shared at the training in Senegal is being used to develop both training modules on curriculum development, and an in-person regional workshop on incorporating gender into agricultural education and extension (Jones \& Christie, 2014).

At the bi-annual RUFORUM conference in Maputo, the key result of the innovATE workshop was the building of a network of agricultural education professionals across the SSA region. Participants at the workshop identified challenges and solutions at their institution or program and then interactively shared best practices at individual institutions that can be adopted by others to develop capacity at their own institutions. The final outcome of this workshop was the generation of a suite of recommended actions for capacity development by each participant for his/her institution. In addition, participants were linked through the CoP to receive further mentoring from colleagues and specialists, so to have access to resources necessary to help support their efforts at institution building. The integration of these various components provided CD at both the individual level, in terms of developing skills for assessment and plans for progress, and at the institutional level, in terms of sharing ideas and creating networks for institutional change.

\section{Conclusions and implications}

Building capacity in AET systems to build capacity in agriculture in sub-Saharan Africa will require activities that focus on each of the three levels of capacity development, as well as activities that support linkages among the levels to build overall system capacity. Through the Learn, Design, Train model for capacity development, innovATE is working to provide information and analysis that supports HICD in AET systems, and that can also provide guidance and input into change at the structural or enabling environment level. Creating traction as a thought leader in any area takes time, especially to become a persuasive voice for reform in AET at the policy and societal levels. However, the innovATE approach and activities undertaken to-date, including those described in this paper have begun to raise important questions about how to best support integrated capacity development. Based on the three-level framework of capacity development used here, there are (at least) three avenues of entry for developing integrated AET capacity: 
- Individual level: by generating a critical mass of individuals with enhanced capacity, or by enhancing the capacity of important change agents who have either the voice or authority to enable change.

- Institutional level: by creating strong institutions that can in turn exert influence over the enabling environment and by simultaneously using these institutions with enhanced capacity to strengthen the capacity of the people who work with and within them.

- Enabling environment: by influencing policy to open up spaces for AET capacity development that will trickle down to the institutional and human level.

InnovATE efforts focus at the individual and institutional capacity development levels, with limited scope or impact on addressing CD in the enabling environment. This leads to three critical questions. First, is innovATE's approach of focusing on the human and institutional levels, the most effective way to bring about a paradigm shift in AET capacity development? Less than three years into program implementation, it is difficult to judge whether innovATE has been able to effect change at the enabling environment level - change which indeed can take much time. Secondly, should innovATE instead change its emphasis and turn more attention to developing capacity in the enabling environment as a more effective way to develop capacity throughout AET systems? This could be especially important in many African societies, which may be rooted in hierarchical cultures and more traditional theories of development change. Finally, how do we best address capacity development in the enabling environment?

One key finding of many of innovATE's Learn and Design activities is that an important barrier to effective capacity development in AET systems is that AET bridges agriculture and education. In many countries, this makes it difficult to identify which actors in the enabling environment, and often which institutions, are responsible for AET capacity development. Too often, this question is posed by both sides, resulting in neither taking leadership nor ownership over the AET system and HICD within it. This deflection of responsibility is further compounded in the African context, where the education and agriculture sectors are often split into completely independent ministries (at the government level), with incompatible or non-synergistic policies and frameworks, and little communication between them. The key question is about who should bear the cost and effort of capacity development in the AET system, especially in resource-poor contexts, where separate (responsible) government ministries may have little incentive to work together. These structural divides in the enabling environment increase the importance of integrated training and planning for individuals and institutions within the AET system.

As innovATE has engaged in AET system capacity building across levels through Train activities, it has become increasingly apparent that cross-cutting approaches to training and institutional change must bridge the silos of agriculture and education. Instead of separating agricultural activities from knowledge about agricultural activities, it is important to take a systems approach to agricultural capacity development. The agricultural knowledge and information systems (AKIS) framework situates the AET system within broader capacity development in agriculture to support economic growth, and to reduce poverty and hunger. This framework incorporates three pillars: education, research and extension. Although AET systems contribute directly to the education pillar of the three, CD in AET systems is also complementary to and synergistic with CD in the other pillars, and in particular in agricultural extension systems. The Modernizing Extension and Advisory Services (MEAS) project, a sister program to innovATE and also funded by USAID's 
Bureau of Food Security, focuses directly on developing capacity in extension systems. African extension systems are notoriously weak, having suffered from the reduced public investment throughout the 1980s and 90s; they are understaffed, underpaid and lack incentives or up-to-date, regular trainings. It is therefore important to carefully consider how innovATE can and should work with MEAS and other capacity development programs in agricultural extension to increase efficiencies and capacity for African extension and community engagement.

Beyond AKIS, it is also worth considering the applicability of evolving agricultural innovation systems' (AIS) frameworks to CD approaches in African AET systems (Rajalahti, Janssen \& Pehu, 2008). AIS potentially provides the flexibility to step beyond (sometimes) rigid boundaries of research, teaching and extension, engaging in a flexible approach that incorporates a multitude of public and private sector actors to foster innovation in agricultural systems. Applying AIS to AET systems could give rise to the necessary plurality of locally-adapted models of CD for African contexts.

CD is a process with multiple roads to success. But sustainable success will only be achieved when interventions and investments are made across multiple levels and throughout the education continuum including primary and secondary schools, higher education, and youth and workforce development programs. Successful impact of innovATE (and other initiatives) on developing capacity in African AET systems will take time - for instance, it can take many years to fully develop and institute a new or revised curriculum. Indeed, there is growing realization that CD as a whole is a long-term process, and can often be undercut by the desires and needs to realize short-term impacts (Lopes \& Theisohn, 2003). However, impact must be considered at multiple timescales and can be generated through integrative, multi-stakeholder approaches. These approaches should include working with African leaders and policymakers and to engage with $\mathrm{CD}$ efforts through CAADP while simultaneously finding ways to engage the marginalized and most food insecure in capacity development. With $43 \%$ of the population of SSA aged 15 years or less, food security challenges will not lessen (Population Reference Bureau, 2014). As the continent with the fastest growing population, and the vast majority still employed in the agricultural sector, improving food security will depend much on developing the capacity of those entering or soon-to-enter the workforce. Although innovATE's approach shows one way forward for Africa in AET systems, there are many other pieces of this CD challenge that still need to be met.

\section{Acknowledgements}

The authors appreciate the significant work undertaken by various members of the innovATE program consortium, including partners from the Virginia Polytechnic Institute and State University, the Pennsylvania State University, the University of Florida and Tuskegee University. Additionally, the authors would like to acknowledge the collaboration of multiple stakeholders across the African continent who participated in and contributed to the success of the activities outlined in this paper. Finally, the authors thank the Ohio State University Extension: Africa group who pulled together an excellent array of professionals to further develop ways forward for the enhancement of African agricultural extension and related services.

\section{Acknowledgement and disclaimer}


InnovATE was made possible by the United States Agency for International Development and the generous support of the American people through USAID Cooperative Agreement No. AID-OAAL-12-00002. However, this paper is not official U.S. Government information and does not represent the views or positions of the U.S. Agency for International Development or the U.S. government.

\section{References}

Acker, D. \& Gasperini, L. (2009).

Education for rural people: the role of education, training and capacity development in poverty reduction and food security. Rome: Food and Agriculture Organization of the United Nations (FAO).

AGRA (2013).

Africa agriculture status report: focus on staple crops. Alliance Nairobi: for a Green Revolution in Africa (AGRA).

Baharanyi, N., Karki, L.B., \& Mutaleb, M. (2014).

Democratic Republic of the Congo: AET background study. InnovATE Country Study. Accessed online at: http://www.oired.vt.edu/innovate/country-series.php

Bindraban, P. S., Loffler, H., \& Rabbinge, R. (2008).

How to close the ever widening gap of Africa's agriculture. International Journal of Tecbnology and Globalisation, Vol. 4(3), 276-295.

Bolger, J. (2000).

Capacity development: why, what and how. Capacity Development Occasional Series, 1(1), 1-8. CIDA (Canadian International Development Agency), Gatineau, Quebec.

Brooks, K., Zorya, S. \& Gautam, A. (2012).

Chapter 5: Jobs for Africa's youth. In: IFPRI. (2012).

Global food policy report. Washington DC: International Food Policy Research Institute (IFPRI).

Brooks, S., Leach, M., Lucas, H., \& Millstone, E. (2009).

Silver bullets, grand challenges and the new philanthropy. STEPS Working Paper 24. Brighton, UK: STEPS Centre.

Eicher, C., \& Haggblade, S. (2013).

Capacity development for Modernizing African Food Systems (MAFS). Michigan State University. East Lansing, MI

Evenson, R. E., \& Gollin, D. (2003).

Assessing the impact of the Green Revolution, 1960 to 2000. Science, Vol. 300 (5620), 758762.

FAO. (2010).

Capacity development now - FAO's approach to sustainability. Accessed online from http://www.fao.org/fileadmin/user upload/capacity building/img/1110 fcd brochure fi nal web NO INSERT.pdf

FARA (2007).

Africa's capacity to build buman and institutional capacity for the agricultural industry. Accra: Ghana.

Feed the Future (2014). 
Feed the Future Progress Report 2014. Accessed online from http://feedthefuture.gov/sites/default/files/resource/files/2014\%20Feed $\% 20$ the $\% 20$ Futur e $\% 20$ Progress $\% 20$ Report $\% 20 \% 283 \% 29$.pdf

Friis-Hansen, E. (2000).

Agricultural policy in Africa after adjustment. Food and Agriculture Organization of the United Nations. Rome: Italy.

Gilboy, A., Flora, C., Raphael, R. \& Pathak, B. (2010).

Agriculture long-term training: assessment and design recommendations. Washington, DC: United States Agency for International Development (USAID).

Godfray, H. C. J., Beddington, J. R., Crute, I. R., Haddad, L., Lawrence, D., Muir, J. F., Pretty, J., Robinson, S., Thomas, S. M. \& Toulmin, C. (2010).

Food security: the challenge of feeding 9 billion people. Science, 327(5967), 812-818.

Horton, D. (1999).

Building capacity in planning, monitoring, and evaluation: Lessons from the field. Knowledge, Technology, and Policy, 11(4): 152-188.

Jones, K., \& Christie, M.E. 2014.

Strategies and tools for integrating gender into agriculture and nutrition curriculum: Symposium report.

InnovATE Report. Accessed online at:

http://www.oired.vt.edu/innovate/documents/Senegal $\% 20$ gender $\% 20$ symposium $\% 20$ repo rt 72114 Final.pdf

Jones, R.J., Brown, K., Byerlee, D., Kramer-LeBlanc, C., Sammons, D., and Stoecker, B. (2012).

BIFAD review of the Collaborative Research Support Program (CRSP) model. Washington, DC: United States Agency for International Development (USAID).

Lechtenberg, V., Ayeni, A., Christy, R. \& Kramer-Leblanc, C. (2014).

BIFAD review of strategic human and institutional capacity development (HICD) issues and the role of USAID and Title XII under the Feed the Future programs. Accessed online from https://scms.usaid.gov/sites/default/files/documents/1867/BIFAD-

HICD $\% 20 \% 20$ Final $\% 20$ Report $\% 2003-31-14 . p d f$

Lopes, C. \& Theisohn, T. (2003).

Ownership, leadership, and transformation : can we do better for capacity development? Earthscan. New York: UNDP.

NEPAD. (2013a).

Agriculture in Africa: transformation and outlook. New Partnership for African Development. Johannesburg: South Africa. Accessed online from http://www.nepad.org/system/files/Agriculture $\% 20 \mathrm{in} \% 20$ Africa.pdf

NEPAD. (2013b).

Annual report 2013. Johannesburg: South Africa. Accessed online from http://www.nepad.org/system/files/NEPAD AR English.pdf

NEPAD. (2014).

Capacity development for CAADP country teams - building coalitions and networks for

OECD. (2006). agricultural transformation. Accessed online at: http://caadp.net/content/resources

The Challenge of Capacity Development: Working Toward Good Practice. Development Assistance Committee. Paris: OECD.

Otoo, S., Agapitova, N., \& Behrens, J. (2009). 
The Capacity Development Results Framework: A strategic and results-oriented approach to learning for capacity development. Washington, DC: World Bank.

Population Reference Bureau. (2014).

World Population Data Sheet. Accessed online from

http:/ /www.prb.org/DataFinder/Geography/Data.aspx?loc $=247$

Rajalahti, R., Janssen, W., \& Pehu, E. (2008).

Agricultural innovation systems: from diagnostics toward operational practices. Washington, DC: World Bank.

Spielman, D. J., Ekboir, J., Davis, K., \& Ochieng, C. M. (2008).

An innovation systems perspective on strengthening agricultural education and training in sub-Saharan Africa. Agricultural systems, 98(1), 1-9.

Staatz, J. M. \& Dembélé, N. N. (2008).

Agriculture for Development in Sub-Saharan Africa. Washington, DC: World Bank. Accessed online at: https://openknowledge.worldbank.com/handle/10986/9043

USAID. (2010).

Human and institutional capacity development handbook. Washington, D.C.: United States Agency for International Development.

World Bank. (1981). Accelerated development in sub-Saharan Africa: an agenda for action. Washington, DC: World Bank.

Zseleczky, L., Van Houweling, E., \& Christie, M.E. (2013).

Preliminary study: Gender, higher education and AET. InnovATE Thematic Study. Accessed online from http://www.oired.vt.edu/innovate/documents/Crosscutting $\% 20$ Studies $/ 924$ 13\%20VT $\% 20$ Gender, $\% 20$ Higher $\% 20$ Education $\% 20$ and $\% 20 \mathrm{AE}$ T.pdf 